\title{
Semi-active control of an integrated full-car suspension with seat suspension and driver body model using ER dampers
}

\author{
Haiping Du \\ School of Electrical, Computer and \\ Telecommunications Engineering, \\ University of Wollongong, \\ Wollongong, NSW 2522, Australia \\ E-mail: hdu@uow.edu.au
}

\author{
Weihua Li \\ School of Mechanical, Materials and \\ Mechatronic Engineering, \\ University of Wollongong, Wollongong, \\ NSW 2522, Australia \\ E-mail: weihuali@uow.edu.au
}

\author{
Nong Zhang* \\ Mechatronics and Intelligent Systems, \\ University of Technology, \\ Sydney, P.O. Box 123, \\ Broadway, NSW 2007, Australia \\ E-mail: Nong.Zhang@uts.edu.au \\ and
}

State Key Laboratory for Advanced Vehicle Body Design

and Manufacturing, Hunan University, Hunan 410082, China

${ }^{*}$ Corresponding author

\begin{abstract}
In this paper, an integrated vehicle semi-active suspension control system that includes a full-car suspension model (7 Degree-Of-Freedom (DOF)), a seat suspension model (2 DOF) and a driver body model (4 DOF) is developed. $\mathrm{A}_{\infty}$ static output feedback controller which only uses measurable variables as feedback signals is designed to improve vehicle ride comfort performance in terms of driver head acceleration under constraints of actuator saturation, suspension deflection limitation and road holding capability. The controller design conditions, which are expressed as Linear Matrix Inequalities (LMIs) are derived by dealing with each control input separately under a common Lyapunov function, so that a feasible solution can be found for the integrated high order system that has five control inputs and ten control outputs; each control input may require different feedback signals and have different saturation limitations. Furthermore, a semiactive control strategy is applied to implement the proposed control system using electrorheological (ER) dampers. Numerical simulations are used to evaluate the
\end{abstract}


improvement of ride comfort performance in terms of driver head acceleration responses under typical road disturbances.

Keywords: integrated semi-active control; ER damper; vehicle suspension; seat suspension; driver body model.

Reference to this paper should be made as follows: Du, H., Li, W. and Zhang, N. (2013) 'Semi-active control of an integrated full-car suspension with seat suspension and driver body model using ER dampers', Int. J. Vehicle Design, Vol. 63, Nos. 2/3, pp.159-184.

Biographical notes: Haiping Du received his $\mathrm{PhD}$ in Mechanical Design and Theory from Shanghai Jiao Tong University, Shanghai, PR China, in 2002. He is currently a Senior Lecturer at the University of Wollongong, Australia. Previously, he worked as a research fellow in the Faculty of Engineering, University of Technology, Sydney (2005-2009), a Post-Doctoral Research Associate at the Imperial College, London (2004-2005) and at the University of Hong Kong (2002-2003), respectively. His research interests include vehicle dynamics and control, robust control theory and engineering applications, soft computing, model and controller reduction, smart materials and structures.

Weihua Li obtained his BEng (1992) and MEng (1995) from the University of Science and Technology of China (USTC) and his PhD (2001) from Nanyang Technological University (NTU), Singapore (2001). After two year's postdoctoral training in NTU (Singapore), he joined the University of Wollongong (UOW) as a full-time academic. He is currently working as director of the Engineering Manufacturing Research Strength and as Discipline Advisor for Mechatronic Engineering at UOW. He has multi-disciplinary areas of expertise, including smart materials and structures, microfluidics, intelligent mechatronics and dynamics and vibration control. He has co-authored more than 160 papers and delivered many plenary or invited talks at various international conferences. He is currently serving as editorial board member for more than eight international journals.

Nong Zhang received his BE in 1982 from the Northeastern University, his ME in 1984 from Shanghai Jiao Tong University, China and his PhD in 1989 from the University of Tokyo, Japan. He worked at several prestigious universities in China, Japan, the USA and Australia before joining the Faculty of Engineering and Information Technology of the University of Technology, Sydney, in 1995. Since 2009, he has been Professor of Mechanical Engineering at the School of Electrical, Mechanical and Mechatronic Systems. For more than 20 years, he has been involved in research in areas of dynamics and control of automotive systems, including powertrains with various types of transmissions, hybrid propulsion systems for HEVs, vehicle dynamics, passive and active suspensions and mechanical vibration, including experimental modal analysis, rotor dynamics and cold rolling mill chatter.

\section{Introduction}

Vehicle suspension systems have been adopted for all passenger and commercial vehicles to provide ride comfort, road holding and other dynamic functions like supporting vehicle 
weight and maintaining the wheels in an appropriate position on the road surface (Fallah et al., 2009). A vehicle suspension design will generally encounter conflicting requirements in terms of ride comfort, suspension deflection limitation and road holding capability. Till date, three main kinds of suspensions, i.e., passive, active and semi-active suspensions (Hrovat, 1997; Williams, 1997) have been proposed to deal with these conflicting requirements. A passive suspension is simple, reliable and cost-effective. However, it cannot provide controllable damping force and thus, its performance is inevitably limited. While maintaining the geometric and dynamical properties of a passive suspension structure, an active or semi-active device is considered for incorporation in modern suspension structures to meet the conflicting requirements. Active and semi-active suspensions are attracting more attention in both academia and the industry for improving vehicle ride comfort and road holding (Hrovat, 1997; Williams, 1997; Guglielmino et al., 2008). In particular, semi-active suspensions offer desirable performance enhanced by active suspensions without requiring high power consumption and expensive hardware. In recent years, semi-active suspension has been studied by many researchers using magnetorheological (MR) dampers (Choi et al., 2002; Du et al., 2005; Wang et al., 2008; Poussot-Vassal et al., 2008; Yu et al., 2009) and electrorheological (ER) dampers (Choi and Kim, 2000; Choi et al., 2000; Choi and Han, 2003; Sung et al., 2007; Sung et al., 2008).

In addition to vehicle suspension, seat suspension has also been adopted in vehicles, in particular, for commercial, industrial, agricultural and other transport purposes (Choi et al., 2000) to provide driver ride comfort, to reduce driver fatigue due to long hours of driving, to alleviate exposure to severe working environments such as rough road conditions and to improve driver safety and health (Tiemessen et al., 2007). Optimisation and control of seat suspensions for reducing vertical vibration has been an active topic of study for decades. Like with vehicle suspension, passive, semi-active and active seat suspensions have also been proposed. Research on passive seat suspension mainly focuses on parameter optimisation for spring stiffness and damping coefficient (Wan and Schimmels, 2003; Lee et al., 2006). Research on active seat suspension mainly focuses on developing advanced control strategies or applying different types of actuators to improve seat suspension performance, taking into account issues like actuator saturation, load variation, time delay and reliability (Wu and Chen, 2004; Bouazara et al., 2006; Maciejewski et al., 2010; Sun et al., 2011). Due to its power consumption advantage, semi-active control of seat suspension using MR and ER dampers has also been extensively studied (Choi et al., 2000; Choi et al., 2003; Choi and Wereley, 2005; Han et al., 2006; Choi and Han, 2007).

Whether the issue is vehicle suspension or seat suspension, one of the common performance requirements is ride comfort. However, it is found from the literature that most of the current research on active/semi-active seat suspension and active/semi-active vehicle suspension is conducted separately. It is, therefore, natural that we get motivated by the idea of integrally controlling both suspensions to provide an enhanced ride comfort performance. Till date, only a few studies (Gundogdu, 2007; Kuznetsov et al., 2011) consider both vehicle suspension and seat suspension together while studying vehicle or seat suspension optimisation problems. On the other hand, for vehicle suspension studies, sprung mass acceleration is normally used as a performance index to evaluate vehicle ride comfort in frequency ranges that are sensitive to human comfort; for seat suspension studies, acceleration of a driver or passenger rigid dummy body is often used to evaluate ride comfort. However, neither sprung mass nor rigid dummy body can precisely reflect human biodynamic properties. Preliminary studies (Choi and Han, 2007; Zhao et al., 2010) show that it is necessary to involve a complicated biomechanical model of the human body in a seated posture to gain a good insight into ride 
comfort performance when designing seat suspensions. Therefore, developing an integrated model which includes vehicle suspension, seat suspension and a human body model and designing an integrated control system will play a significant role in efforts to improve human body ride comfort when sitting in a vehicle.

In this paper, an integrated system that includes a full-car suspension model (7 Degreeof-Freedom (DOF)), a seat suspension model (2 DOF) and a driver body model (4 DOF)) is developed first. Based on this integrated model, a $H_{\infty}$ static output feedback controller is then designed to generate the desired control forces to reduce driver head acceleration under the constraints of actuator saturation, suspension deflection limitation and road holding capability. A static output feedback controller is considered because not all the state variables, in particular, the variables in relation to the human body model, are measurable in practice. As this is a high order system with multiple inputs (five control inputs: four for the vehicle suspension and one for the seat suspension) and multiple outputs (ten control outputs: the driver head acceleration, the four vehicle suspension deflections, one seat deflection and four tyre deflections) and each control input may require different feedback signals and have different saturation limitations, we will deal with each control input separately under a common Lyapunov function to derive the controller design conditions, which are expressed as Linear Matrix Inequalities (LMIs). Furthermore, a semi-active control strategy is applied to implement the proposed control system using ER dampers. Numerical simulations are finally used to validate the effectiveness of the proposed control system.

This paper is organised as follows. In Section 2, the integrated system model is developed. In Section 3, the control system design approach is presented. The simulation results will be provided in Section 4. Finally, conclusions are summarised in Section 5.

The notations used throughout the paper are fairly standard. For a real symmetric matrix $W$, the notation of $W>0(W<0)$ is used to denote its positive- (negative-) definiteness. $\|\cdot\|$ refers to either the Euclidean vector norm or the induced matrix 2-norm. $I$ is used to denote the identity matrix of appropriate dimensions. To simplify notations, ${ }^{*}$ is used to represent a block matrix which is readily inferred by symmetry.

Table 1 Parameters of the seat-driver suspension model

\begin{tabular}{llll}
\hline$c_{s s}$ & damping of seat suspension & $k_{s s}$ & stiffness of seat suspension \\
$c_{c}$ & damping of seat cushion & $k_{c}$ & stiffness of seat cushion \\
$c_{1}$ & damping of buttocks and thighs & $k_{1}$ & stiffness of buttocks and thighs \\
$c_{2}$ & damping of lumbar spine & $k_{2}$ & stiffness of lumbar spine \\
$c_{3}$ & damping of thoracic spine & $k_{3}$ & stiffness of thoracic spine \\
$c_{4}$ & damping of cervical spine & $k_{4}$ & stiffness of cervical spine \\
\hline
\end{tabular}

\section{Integrated system modelling}

The integrated vehicle suspension, seat and driver body model includes a full-car suspension model, a seat suspension model and a driver body model, as shown in Figure 1, where $m_{s}$ is the sprung mass, which represents the car chassis; $m_{f}, m f_{r}, m_{r l}$ and $m_{r r}$ are the unsprung masses for the front left $(f l)$, front right $(f r)$, rear left $(r l)$ and rear right $(r r)$ wheels, respectively; $m_{f}$ is the seat frame mass; $m_{c}$ is the seat cushion mass; the driver body is composed of four mass segments, i.e., the thighs $\left(m_{1}\right)$, the lower torso $\left(m_{2}\right)$, the higher torso $(m)_{3}$ and the head $\left(m_{4}\right)$, where the arms and legs are combined with the upper torso and thighs, respectively. $I_{\phi}$ and $I_{\theta}$ 
are the moments of inertia of the vehicle body for roll and pitch motions, respectively; $\phi$ and $\theta$ are the roll and pitch angles; $z_{s}, z_{u f f}, z_{u f r}, z_{u r l}, z_{u r r}, z_{f}, z_{c}$ and $z_{1 \sim 4}$ are the displacements of the corresponding masses, respectively; $z_{r f f}, z_{r f r}, z_{r r l}$ and $z_{r r r}$ are the road displacement inputs to the four wheels; and $r_{x}$ and $r_{y}$ represent the seat position in relation to the centre of mass. $c_{s f}, c_{s r}$ and $k_{s f}, k_{s r}$ are the dampings and stiffnesses of the car suspension system, respectively; $k_{t,}, k_{t r}$ and $c_{t}$, $c_{t r}$ stand for the compressibilities and dampings of the pneumatic tyres, respectively; and $c_{s}$, $c_{s s}, c_{1 \sim 4}, k_{s}, k_{s s}$ and $k_{1 \sim 4}$ are defined in Table $1 . F_{f f}, F_{f r}, F_{r l}, F_{r r}$ and $F_{s}$ represent the controllable damping forces applied to the car suspension and the seat suspension, respectively.

Figure 1 Integrated full-car suspension, seat suspension and driver body model

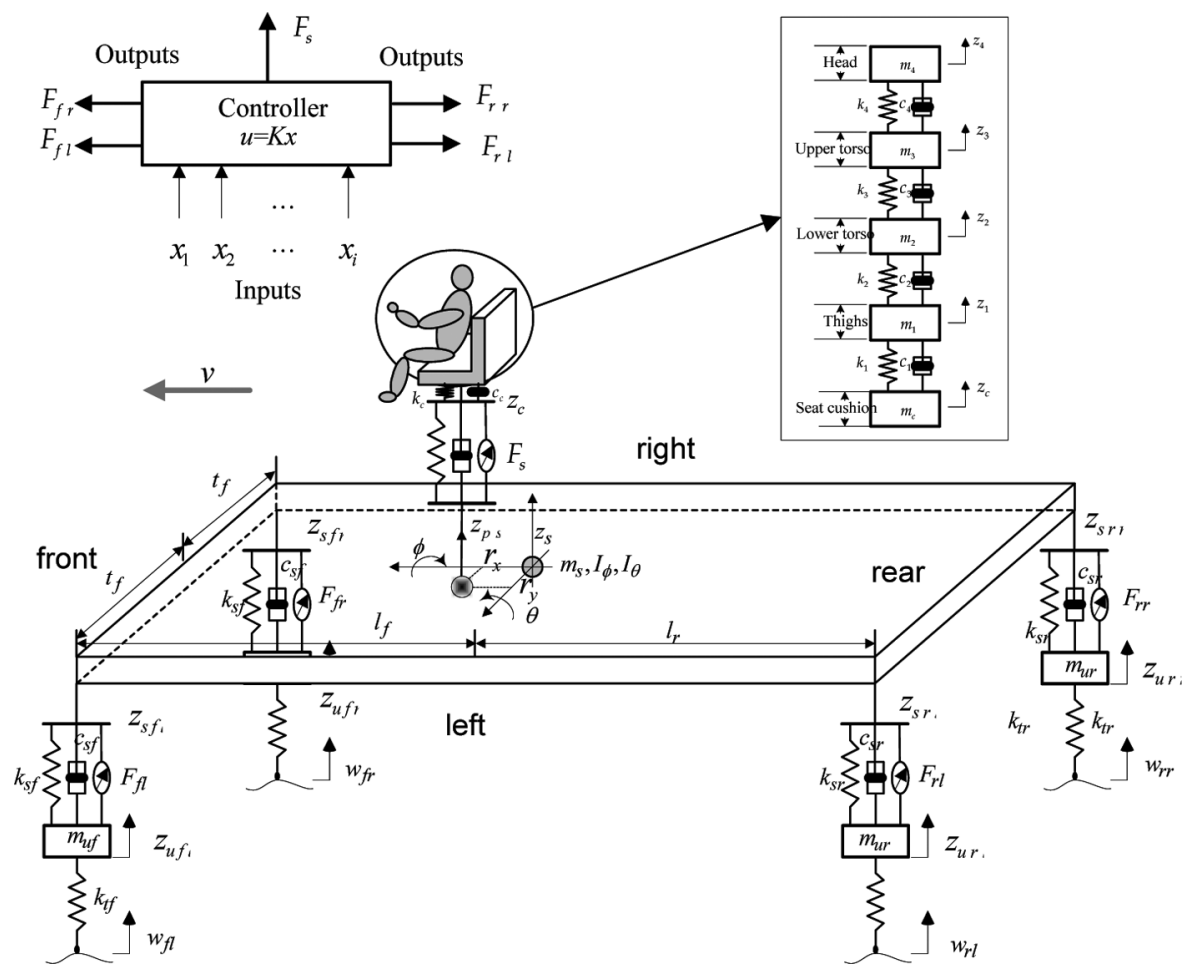

For small angles $\phi$ and $\theta, \sin \phi \approx \phi, \cos \phi \approx 1, \sin \theta \approx \theta, \cos \theta \approx 1$, we use the following approximate linear relationships

$$
\begin{aligned}
& z_{p s}=z_{s}-r_{x} \theta+r_{y} \phi, \\
& z_{s f l}=z_{s}-l_{f} \theta+t_{f} \phi, \\
& z_{s f r}=z_{s}-l_{f} \theta-t_{f} \phi, \\
& z_{s r l}=z_{s}+l_{r} \theta+t_{r} \phi, \\
& z_{s r r}=z_{s}+l_{r} \theta-t_{r} \phi .
\end{aligned}
$$


The passive forces generated between the sprung masses and the unsprung masses can be expressed as

$$
\begin{aligned}
& F_{s f l}=k_{s f}\left(z_{s f l}-z_{u f l}\right)+c_{s f}\left(\dot{z}_{s f l}-\dot{z}_{u f l}\right), \\
& F_{s f r}=k_{s f}\left(z_{s f r}-z_{u f r}\right)+c_{s f}\left(\dot{z}_{s f r}-\dot{z}_{u f r}\right), \\
& F_{s r l}=k_{s r}\left(z_{s r l}-z_{u r l}\right)+c_{s r}\left(\dot{z}_{s r l}-\dot{z}_{u r l}\right), \\
& F_{s r r}=k_{s r}\left(z_{s r r}-z_{u r r}\right)+c_{s r}\left(\dot{z}_{s r r}-\dot{z}_{u r r}\right) .
\end{aligned}
$$

The passive force generated between the cabin floor and the seat frame is

$$
F_{s s}=k_{s s}\left(z_{f}-z_{p s}\right)+c_{s s}\left(\dot{z}_{f}-\dot{z}_{p s}\right) .
$$

The dynamic vertical motion equations for the car's unsprung masses are

$$
\begin{aligned}
& m_{u f l} \ddot{z}_{u f l}=F_{s f l}+F_{f l}-k_{t f}\left(z_{u f l}-z_{r f l}\right), \\
& m_{u f r} \ddot{z}_{u f r}=F_{s f r}+F_{f r}-k_{t f}\left(z_{u f r}-z_{r f r}\right), \\
& m_{u r l} \ddot{z}_{u r l}=F_{s r l}+F_{r l}-k_{t r}\left(z_{u r l}-z_{r r l}\right), \\
& m_{u r r} \ddot{z}_{u r r}=F_{s r r}+F_{r r}-k_{t r}\left(z_{u r r}-z_{r r r}\right) .
\end{aligned}
$$

Similarly, for small angles $\phi$ and $\theta$, the dynamic vertical motion equations for the car chassis can be linearly formalised as

$$
\begin{aligned}
m_{s} \ddot{z}_{s}= & -F_{s f l}-F_{s f r}-F_{s r l}-F_{s r r}-F_{f l}-F_{f r}-F_{r l}-F_{r r}+F_{s s}+F_{s}, \\
I_{\theta} \ddot{\theta}= & l_{f} F_{s f l}+l_{f} F_{s f r}-l_{r} F_{s r l}-l_{r} F_{s r r}+l_{f} F_{f l}+l_{f} F_{f r}-l_{r} F_{r l} \\
& -l_{r} F_{r r}-r_{x} F_{s s}-r_{x} F_{s}, \\
I_{\phi} \ddot{\phi}= & -t_{f} F_{s f l}+t_{f} F_{s f r}-t_{f} F_{s r l}+t_{f} F_{s r r}-t_{f} F_{f l}+t_{f} F_{f r}-t_{f} F_{r l} \\
& +t_{f} F_{r r}+r_{y} F_{s s}+r_{y} F_{s} .
\end{aligned}
$$


The dynamic vertical motion equations for the seat suspension and driver body are given by

$$
\begin{aligned}
& m_{f} \ddot{z}_{f}=k_{c}\left(z_{c}-z_{f}\right)+c_{c}\left(\dot{z}_{c}-\dot{z}_{f}\right)-F_{s s}-F_{s}, \\
& m_{c} \ddot{z}_{c}=-k_{c}\left(z_{c}-z_{f}\right)-c_{c}\left(\dot{z}_{c}-\dot{z}_{f}\right)+k_{1}\left(z_{1}-z_{c}\right)-c_{1}\left(\dot{z}_{1}-\dot{z}_{c}\right), \\
& m_{1} \ddot{z}_{1}=-k_{1}\left(z_{1}-z_{c}\right)-c_{1}\left(\dot{z}_{1}-\dot{z}_{c}\right)+k_{2}\left(z_{2}-z_{1}\right)-c_{2}\left(\dot{z}_{2}-\dot{z}_{1}\right), \\
& m_{2} \ddot{z}_{2}=-k_{2}\left(z_{2}-z_{1}\right)-c_{2}\left(\dot{z}_{2}-\dot{z}_{1}\right)+k_{3}\left(z_{3}-z_{2}\right)+c_{3}\left(\dot{z}_{3}-\dot{z}_{2}\right), \\
& m_{3} \ddot{z}_{3}=-k_{3}\left(z_{3}-z_{2}\right)-c_{3}\left(\dot{z}_{3}-\dot{z}_{2}\right)+k_{4}\left(z_{4}-z_{3}\right)+c_{4}\left(\dot{z}_{4}-\dot{z}_{3}\right), \\
& m_{4} \ddot{z}_{4}=-k_{4}\left(z_{4}-z_{3}\right)-c_{4}\left(\dot{z}_{4}-\dot{z}_{3}\right) .
\end{aligned}
$$

The motion equations of the integrated model in terms of mass, damping and stiffness matrices can be formalised as

$$
\begin{aligned}
& M_{u} \ddot{x}_{u}=B_{s}\left(\dot{x}_{s}-\dot{x}_{u}\right)+K_{s}\left(x_{s}-x_{u}\right)+K_{t}\left(w-x_{u}\right)+F_{a} \\
M_{s} \ddot{q}= & L B_{s}\left(\dot{x}_{u}-\dot{x}_{s}\right)+L K_{s}\left(x_{u}-x_{s}\right)-L F_{a}+L_{p}\left(k_{s s} L_{f} x_{d}-k_{s s} L_{p}^{T} q+c_{s s} L_{f} \dot{x}_{d}\right. \\
& \left.-c_{s s} L_{p}^{T} \dot{q}\right)+L_{p} F_{s} \\
& M_{d} \ddot{x}_{d}=B_{d} \dot{x}_{d}+K_{d} x_{d}+L_{f}^{T} k_{s s} L_{p}^{T} q+L_{f}^{T} c_{s s} L_{p}^{T} \dot{q}-L_{f}^{T} F_{s}
\end{aligned}
$$

where

$$
\begin{aligned}
M_{u} & =\left[\begin{array}{ccc}
m_{s} & 0 & 0 \\
0 & I_{\theta} & 0 \\
0 & 0 & I_{\phi}
\end{array}\right], M_{s}=\left[\begin{array}{cccc}
m_{u f l} & 0 & 0 & 0 \\
0 & m_{u f r} & 0 & 0 \\
0 & 0 & m_{u r l} & 0 \\
0 & 0 & 0 & m_{u r r}
\end{array}\right], \\
M_{d} & =\left[\begin{array}{rrrrrr}
m_{f} & 0 & 0 & 0 & 0 & 0 \\
0 & m_{c} & 0 & 0 & 0 & 0 \\
0 & 0 & m_{1} & 0 & 0 & 0 \\
0 & 0 & 0 & m_{2} & 0 & 0 \\
0 & 0 & 0 & 0 & m_{3} & 0 \\
0 & 0 & 0 & 0 & 0 & m_{4}
\end{array}\right], B_{s}=\left[\begin{array}{cccc}
c_{s f l} & 0 & 0 & 0 \\
0 & c_{s f r} & 0 & 0 \\
0 & 0 & c_{s r l} & 0 \\
0 & 0 & 0 & c_{s r r}
\end{array}\right],
\end{aligned}
$$




$$
\begin{aligned}
& K_{s}=\left[\begin{array}{cccc}
k_{s f l} & 0 & 0 & 0 \\
0 & k_{s f r} & 0 & 0 \\
0 & 0 & k_{s r l} & 0 \\
0 & 0 & 0 & k_{s r r}
\end{array}\right], \quad K_{t}=\left[\begin{array}{cccc}
k_{t f} & 0 & 0 & 0 \\
0 & k_{t f} & 0 & 0 \\
0 & 0 & k_{t r} & 0 \\
0 & 0 & 0 & k_{t r}
\end{array}\right], \\
& B_{d}=\left[\begin{array}{cccccc}
-c_{s s}-c_{c} & c_{c} & 0 & 0 & 0 & 0 \\
c_{c} & -c_{c}-c_{1} & c_{1} & 0 & 0 & 0 \\
0 & c_{1} & -c_{1}-c_{2} & c_{2} & 0 & 0 \\
0 & 0 & c_{2} & -c_{2}-c_{3} & c_{3} & 0 \\
0 & 0 & 0 & c_{3} & -c_{3}-c_{4} & c_{4} \\
0 & 0 & 0 & 0 & c_{4} & -c_{4}
\end{array}\right] \text {, } \\
& K_{d}=\left[\begin{array}{cccccc}
-k_{s s}-k_{c} & k_{c} & 0 & 0 & 0 & 0 \\
k_{c} & -k_{c}-k_{1} & k_{1} & 0 & 0 & 0 \\
0 & k_{1} & -k_{1}-k_{2} & k_{2} & 0 & 0 \\
0 & 0 & k_{2} & -k_{2}-k_{3} & k_{3} & 0 \\
0 & 0 & 0 & k_{3} & -k_{3}-k_{4} & k_{4} \\
0 & 0 & 0 & 0 & k_{4} & -k_{4}
\end{array}\right] \text {, } \\
& L=\left[\begin{array}{cccc}
1 & 1 & 1 & 1 \\
-l_{f} & -l_{f} & l_{r} & l_{r} \\
t_{f} & -t_{f} & t_{r} & -t_{r}
\end{array}\right], \quad L_{p}=\left[\begin{array}{c}
1 \\
-r_{x} \\
r_{y}
\end{array}\right], \quad L_{f}=\left[\begin{array}{llllll}
1 & 0 & 0 & 0 & 0 & 0
\end{array}\right], \\
& q=\left[\begin{array}{lll}
z_{s} & \theta & \phi
\end{array}\right]^{T}, \quad x_{s}=\left[\begin{array}{llll}
z_{s f l} & z_{s f r} & z_{s r l} & z_{s r r}
\end{array}\right]^{T}, \\
& x_{u}=\left[\begin{array}{llll}
z_{u f l} & z_{u f r} & z_{u r l} & z_{u r r}
\end{array}\right]^{T}, \quad x_{d}=\left[\begin{array}{llllll}
z_{f} & z_{c} & z_{1} & z_{2} & z_{3} & z_{4}
\end{array}\right]^{T}, \\
& w=\left[\begin{array}{llll}
z_{r f l} & z_{r f r} & z_{r r l} & z_{r r r}
\end{array}\right]^{T}, \quad F_{a}=\left[\begin{array}{llll}
F_{f l} & F_{f r} & F_{r l} & F_{r r}
\end{array}\right]^{T} \text {. }
\end{aligned}
$$

By using the following relationships between vectors, $z_{f}=L_{f} x_{d}, z_{p s}=L_{p}^{T} q, x_{s}=L^{T} q$, $F_{s s}=k_{s s} L_{f} x_{d}-k_{s s} L_{p}^{T} q+c_{s s} L_{f} \dot{x}_{d}-c_{s s} L_{p}^{T} \dot{q}$, (24)-(26) can be further formalised as

$$
M_{p} \ddot{p}+B_{p} \dot{p}+K_{p} p=K_{w} w+K_{f} u,
$$

where

$$
p=\left[\begin{array}{lll}
x_{u} & q & x_{d}
\end{array}\right]^{T}, \quad M_{p}=\left[\begin{array}{ccc}
M_{u} & 0 & 0 \\
0 & M_{s} & 0 \\
0 & 0 & M_{d}
\end{array}\right],
$$




$$
\begin{gathered}
B_{p}=\left[\begin{array}{ccc}
B_{s} & -B_{s} L^{T} & 0 \\
-L B_{s} & L B_{s} L^{T}+L_{p} c_{s s} L_{p}^{T} & -L_{p} c_{s s} L_{f} \\
0 & -L_{f}^{T} c_{s s} L_{p}^{T} & -B_{d}
\end{array}\right], \\
K_{p}=\left[\begin{array}{ccc}
K_{s}+K_{t} & -K_{s} L^{T} & 0 \\
-L K_{s} & L K_{s} L^{T}+L_{p} k_{s s} L_{p}^{T} & -L_{p} k_{s s} L_{f} \\
0 & -L_{f}^{T} k_{s s} L_{p}^{T} & -K_{d}
\end{array}\right], \\
K_{w}=\left[\begin{array}{c}
K_{t} \\
0 \\
0
\end{array}\right], \quad K_{f}=\left[\begin{array}{cc}
I & 0 \\
-L & L_{p} \\
0 & -L_{f}^{T}
\end{array}\right], \quad u=\left[\begin{array}{l}
F_{a} \\
F_{s}
\end{array}\right] .
\end{gathered}
$$

By defining the state vector as $x=\left[\begin{array}{ll}p^{T} & \dot{p}^{T}\end{array}\right]^{T}$, we can write the dynamic equations (27) into a state-space form:

$$
\dot{x}=A x+B_{w} w+B u,
$$

where $A=\left[\begin{array}{cc}0 & I \\ -M_{p}^{-1} K_{p} & -M_{p}^{-1} B^{p}\end{array}\right], \quad B_{w}=\left[\begin{array}{c}0 \\ M_{p}^{-1} K_{w}\end{array}\right], \quad B=\left[\begin{array}{c}0 \\ M_{p}^{-1} K_{f}\end{array}\right]$.

Note that the roll and pitch angles are assumed to be smaller in deriving the system equations, so that a linear model can be approximately obtained. This linear model will largely benefit the controller design, as the advanced linear control theory can be easily applied. However, for a practical passive suspension system, this assumption may not exist, particularly when the vehicle is driving on a rough surface or off-road. Thus, a more generic nonlinear model that allows bigger roll and pitch angles should be used when doing a system dynamics analysis. Nevertheless, for a semi-active or an active suspension, this assumption is acceptable, because the roll and pitch angles are controlled to be smaller with appropriate control actions.

\section{Control system design}

\subsection{Electrorheological damper}

In Equation (28), the control input vector $u$ represents the control forces applied to the vehicle suspension and the seat suspension. These forces can be generated through actuators, such as electro-hydraulic actuators or linear permanent magnet motors, or controllable dampers, such as MR dampers or ER dampers. As an example of semi-active control, this paper will apply the ER damper to generate the required forces.

A cylindrical type of ER damper, which is applicable to a middle-sized passenger vehicle, was designed and manufactured in Choi and Han (2003). The ER damper can produce additional an damping force owing to the yield stress of the ER fluid if a certain level of the electric field is supplied to the ER damper; this damping force of the ER damper can be continuously tuned by controlling the intensity of the electric field. 
The damping force of the proposed ER damper is given as (Choi and Han, 2003)

$$
F=k_{e} x_{p}+c_{e} \dot{x}_{p}+F_{E R},
$$

where $k_{e}$ is the effective stiffness due to the gas pressure, $c_{e}$ is the effective damping due to the fluid viscosity, $x_{p}$ and $\dot{x}_{p}$ are the excitation displacement and velocity, respectively and $F_{E R}$ is the field-dependent damping force which is tunable as a function of the applied electric field. The controllable damping force $F_{E R}$ is expressed by

$$
F_{E R}=\left(A_{p}-A_{r}\right) 2 \frac{l}{h} \alpha E^{\beta} \operatorname{sgn}\left(\dot{x}_{p}\right)
$$

where $A_{p}$ and $A_{r}$ represent the piston and the piston rod areas, respectively, $\operatorname{sgn}(\cdot)$ is a sign function, $l$ is the electrode length, $h$ is the electrode gap and $E$ is the electric field. The $\alpha$ and $\beta$ are intrinsic values of the ER fluid to be experimentally determined. Since the dynamic motion of ER fluid between the inner and outer cylinder of the ER damper can be regarded as flow mode, the intrinsic values $\alpha$ and $\beta$ of the employed ER fluids are experimentally determined by using a flow mode type electroviscometer. In this study, the field-dependent yield stresses of the ER fluid, which was experimentally obtained by $565.2 \mathrm{E}^{1.55} \mathrm{~Pa}$ (Choi and Han, 2003), where the unit of $E$ is $\mathrm{kV} / \mathrm{mm}$, will be used.

\subsection{Control objectives}

For a suspension design with the driver body model, the performance of ride comfort will be mainly described by the driver head acceleration (Zhao et al., 2010; Sun et al., 2011) and therefore, the driver head acceleration.

$$
z_{g 1}=\ddot{z}_{4}=C_{1} x
$$

where $C$ is the last row of the A matrix and will be defined as one control output.

For vehicle suspension systems, on the other hand, the suspension deflection limitation and road holding ability should be considered apart from the ride comfort performance. To keep the suspension deflection within its limitations, the car suspension deflections $z_{s i}-z_{u i}, \quad i \in\{f l, f r, r l, r r\}$ and the seat suspension deflection $z_{c}-z_{p s}$, are required to be smaller. Similarly, to keep the wheel in contact with the ground, the wheel vertical displacements $z_{u i}, i \in\{f l, f r, r l, r r\}$ are required to be smaller, so that a good road holding performance can be achieved. Thus, we will define the suspension deflections and wheel displacements as two other control outputs, that is,

$$
z_{g 2}=\left[\begin{array}{lllll}
z_{s f l}-z_{u f l} & z_{s f r}-z_{u f r} & z_{s r l}-z_{u r l} & z_{s r r}-z_{u r r} & z_{c}-z_{p s}
\end{array}\right]^{T}=C_{2} x,
$$

and

$$
z_{g 3}=\left[\begin{array}{llll}
z_{u f l} & z_{u f r} & z_{u r l} & z_{u r r}
\end{array}\right]^{T}=C_{3} x,
$$

where $C_{2}$ and $C_{3}$ can be defined appropriately in terms of the state vector $x$. For example, the first row of $C_{2}$ can be defined as $\left.\left[\begin{array}{cccccccc}-1 & 0 & 0 & 0 & 1 & -l_{f} & t_{f} & {[0}\end{array}\right]_{1 \times 18}\right]$, and the first row of $C_{3}$ is defined as $\left[\begin{array}{ll}1 & {[0]_{1 \times 25}}\end{array}\right]$. 
As the three control objectives are in conflict with each other, they cannot be optimised at the same time. To compromise these control objectives and convert the multiple objective problem into a single objective problem in the controller design procedure, the final control output is defined as

$$
z=\left[\begin{array}{c}
z_{g 1} \\
\alpha_{2} z_{g 2} \\
\alpha_{3} z_{g 3}
\end{array}\right]=\left[\begin{array}{c}
C_{1} \\
\alpha_{2} C_{2} \\
\alpha_{3} C_{3}
\end{array}\right] x=C x,
$$

where $\alpha_{2}$ and $\alpha_{3}$ are weighting parameters used to provide trade-offs among $z_{g 1}$ to $z_{g 3}$.

To achieve a good suspension performance and make the controller perform adequately for a wide range of road disturbances, the $L_{2}$ gain between the road disturbance input $w$ and the control output $z$, is defined as

$$
\left\|T_{z w}\right\|_{\infty}=\sup _{\|w\|_{2} \neq 0} \frac{\|z\|_{2}}{\|w\|_{2}},
$$

where $\|z\|_{2}^{2}=\int_{0}^{\infty} z^{T} z d t$ and $\|w\|_{2}^{2}=\int_{0}^{\infty} w^{T} w d t$, is chosen as the performance measure. A small value of $\left\|T_{z w}\right\|_{\infty}$ generally means a small value of driver head acceleration under energy-limited road disturbances and reasonable suspension deflection and road holding requirements. The control objective is to design a controller in such a way that the closed-loop system is asymptotically stable and the performance measure (35) is minimised.

\subsection{Controller design}

To achieve the required objectives, a state feedback controller can be designed as

$$
u=K x
$$

where $K$ is the feedback gain matrix to be found. However, the implementation of a state feedback controller assumes that all the state variables are measurable. This is not practical, in particular, for a high-DOF human body model where most of the state variables, such as torso displacements and velocities, are not measurable or are not suitable for measurement when a driver is driving. Therefore, a static output feedback controller, which only uses available measurements, will be designed for the integrated system.

The static output feedback controller is designed as

$$
u=K C_{s} x
$$

where $C_{s}$ is a constant matrix used to define the available state variables. For example, if only $x_{1}$ in (28) is available for feedback, then $C_{s}$ is defined as $C_{s}=\left[\begin{array}{ll}1 & {[0]_{1 \times 15}}\end{array}\right]$.

In addition, actuator saturation needs to be considered because all the actuators are practically limited by their physical capabilities. In general, a control input with saturation limitation is defined as $\bar{u}=\operatorname{sat}(u)$, where $\operatorname{sat}(u)$ is a saturation function defined as 


$$
\operatorname{sat}(u)= \begin{cases}-u_{\lim } & \text { if } u<-u_{\lim } \\ u & \text { if }-u_{\lim } \leq u \leq u_{\lim }, \\ u_{\lim } & \text { if } u>u_{\lim }\end{cases}
$$

where $u_{\text {lim }}$ is the control input limit. Taking actuator saturation into account, equation (28) is modified as

$$
\dot{x}=A x+B_{w} w+B \bar{u} .
$$

To deal with the saturation problem in the controller design process, the following lemma will be used.

Lemma $1 \mathrm{Kim}$ and Jabbari (2002). For the saturation constraint defined by (38), as long as $|u| \leq \frac{u_{\text {lim }}}{\varepsilon}$, we have

$$
\left\|\bar{u}-\frac{1+\varepsilon}{2} u\right\| \leq \frac{1-\varepsilon}{2}\|u\|,
$$

and hence,

$$
\left[\bar{u}-\frac{1+\varepsilon}{2} u\right]^{T}\left[\bar{u}-\frac{1+\varepsilon}{2} u\right] \leq\left(\frac{1-\varepsilon}{2}\right)^{2} u^{T} u,
$$

where $0<\varepsilon<1$ is a given scalar.

To apply Lemma 1 in the next section, system (39) is further written as

$$
\begin{gathered}
\dot{x}=A x+B_{w} w+B \frac{1+\varepsilon}{2} u+B\left(\bar{u}-\frac{1+\varepsilon}{2} u\right) \\
=A x+B_{w} w+B \frac{1+\varepsilon}{2} u+B v,
\end{gathered}
$$

where $v=\bar{u}-\frac{1+\varepsilon}{2} u$.

To derive the main result, the following lemma is also used.

Lemma 2 Zhou and Khargonekar (1988). For any matrices (or vectors) $X$ and $Y$ with appropriate dimensions, we have

$$
X^{T} Y+Y^{T} X \leq \epsilon X^{T} X+\epsilon^{-1} Y^{T} Y,
$$

where $\epsilon>0$ is any scalar.

To find the controller gain matrix $K$ in (37), we now define a Lyapunov function for system (39) as

$$
V(x)=x^{T} P x,
$$


where $P$ is a positive definite matrix. By differentiating (44) and using (42), we obtain

$$
\begin{aligned}
\dot{V}(x)= & \dot{x}^{T} P x+x^{T} P \dot{x} \\
= & {\left[A x+B_{w} w+B \frac{1+\varepsilon}{2} u+B v\right]^{T} P x } \\
& +x^{T}(t) P\left[A x+B_{w} w+B \frac{1+\varepsilon}{2} u+B v\right] .
\end{aligned}
$$

Since there are five inputs in the system and each input may use different feedback signals and have different saturation limits, we will describe each input separately in deriving the controller design conditions to reduce the possible conservatism. The control input vector is defined as $u=\left[F_{f l}, F_{f r}, F_{r l} F_{r r}, F_{s}\right]^{T}=\left[u_{1}, u_{2}, u_{3}, u_{4}, u_{5}\right]^{T}$, where $u_{i}$ is the $i$ th input, $i=1,2, \ldots, 5$ and hence, $B u=\sum_{i=1}^{5} B_{i} u_{i}=\sum_{i=1}^{5} B_{i} K_{i} C_{s i} x$ can be obtained, where $B_{i}$ is the $i$ th column of $B$ matrix and $C_{s i}$ is used to define the available state variables for the $i$ th input. Then, (45) is replaced by

$$
\begin{aligned}
\dot{V}(x)= & \dot{x}^{T} P x+x^{T} P \dot{x} \\
= & \left\{A x+B_{w} w+\sum_{i=1}^{5}\left[B_{i} \frac{1+\varepsilon_{i}}{2} u_{i}+B_{i} v_{i}\right]\right\}^{T} P x \\
& +x^{T}(t) P\left\{A x+B_{w} w+\sum_{i=1}^{5}\left[B_{i} \frac{1+\varepsilon_{i}}{2} u_{i}+B_{i} v_{i}\right]\right\},
\end{aligned}
$$

where $v_{i}=\bar{u}_{i}-\frac{1+\varepsilon}{2} u_{i}$. By using Lemma 1 , Lemma 2 and $u_{i}=K_{i} C_{s i} x$, we have

$$
\begin{aligned}
\dot{V}(x) & \leq x^{T}\left\{A^{T} P+P A+\sum_{i=1}^{5}\left[\left(B_{i} \frac{1+\varepsilon_{i}}{2} K_{i} C_{s i}\right)^{T} P+P B \frac{1+\varepsilon_{i}}{2} K_{i} C_{s i}\right]\right\} x \\
& +w^{T} B_{w}^{T} P x+x^{T} P B_{w} w+\sum_{i=1}^{5}\left(\epsilon_{i} v_{i}^{T} v_{i}+\epsilon_{i}^{-1} x^{T} P B_{i} B_{i}^{T} P x\right) \\
& \leq x^{T}\left\{A^{T} P+P A+\sum_{i=1}^{5}\left[\left(B_{i} \frac{1+\varepsilon_{i}}{2} K_{i} C_{s i}\right)^{T} P+P B_{i} \frac{1+\varepsilon_{i}}{2} K_{i} C_{s i}\right]\right\} x+w^{T} B_{w}^{T} P x . \\
& +x^{T} P B_{w} w+\sum_{i=1}^{5}\left[\epsilon_{i}\left(\frac{1-\varepsilon_{i}}{2}\right)^{2} u_{i}^{T} u_{i}+\epsilon^{-1} x^{T} P B_{i} B_{i}^{T} P x\right] \\
& =x^{T} \Theta x+w^{T} B_{w}^{T} P x+x^{T} P B_{w} w
\end{aligned}
$$


where

$$
\Theta=A^{T} P+P A+\sum_{i=1}^{5}\left[\begin{array}{l}
\left(B_{i} \frac{1+\varepsilon_{i}}{2} K_{i} C_{s i}\right)^{T} P+P B_{i} \frac{1+\varepsilon_{i}}{2} K_{i} C_{s i} \\
+\epsilon_{i}\left(\frac{1-\varepsilon_{i}}{2}\right)^{2} C_{s i}^{T} K_{i}^{T} K_{i} C_{s i}+\epsilon_{i}^{-1} P B_{i} B_{i}^{T} P
\end{array}\right],
$$

and where $0<\varepsilon_{i}<1$ are given scalars and $\epsilon_{i}, i=1,2, \ldots, 5$ are any positive scalars.

Adding $z^{T} z-\gamma^{2} w^{T} w, \gamma>0$, which is a performance index, to the two sides of (46) yields

$$
\begin{aligned}
& \dot{V}(x)+z^{T} z-\gamma^{2} w^{T} w \\
& \leq\left[\begin{array}{ll}
x^{T} & w^{T}
\end{array}\right]\left[\begin{array}{cc}
\Theta+C^{T} C & P B_{w} \\
B_{w}^{T} P & -\gamma^{2} I
\end{array}\right]\left[\begin{array}{l}
x \\
w
\end{array}\right] \\
& =\left[\begin{array}{ll}
x^{T} & w^{T}
\end{array}\right] \Pi\left[\begin{array}{l}
x \\
w
\end{array}\right],
\end{aligned}
$$

where $\Pi=\left[\begin{array}{cc}\Theta+C^{T} C & P B_{w} \\ B_{w}^{T} P & -\gamma^{2} I\end{array}\right]$. It is now deduced from (47) that if $\Pi<0$, then, $\dot{V}(x)+z^{T} z-\gamma^{2} w^{T} w<0$ and then, $\left\|T_{z w}\right\|_{\infty}<\gamma$ with the initial condition $x(0)=0$ (Boyd et al., 1994). When the road disturbance is zero, i.e., $w=0$, it can be inferred from (47) that if $\Pi<0$, then $\dot{V}(x)<0$ and the system (39) with the controller (37) is quadratically stable.

By pre- and post-multiplying $\Pi$ with diag $\left(P^{-1} I\right)$ and its transpose, respectively and defining $Q=P^{-1} W_{i} C_{s i}=C_{s i} Q$ and $Y_{i}=K_{i} W_{i}$, the condition of $\Pi<0$ is equivalent to

$$
\left[\begin{array}{cc}
\Psi+Q C^{T} C Q & B_{w} \\
B_{w}^{T} & -\gamma^{2} I
\end{array}\right]<0
$$

where

$$
\Psi=Q A^{T}+A Q+\sum_{i=1}^{5}\left[\frac{1+\varepsilon_{i}}{2} C_{s i}^{T} Y_{i}^{T} B_{i}^{T}+\frac{1+\varepsilon_{i}}{2} B_{i} Y_{i} C_{s i}+\epsilon_{i}\left(\frac{1-\varepsilon_{i}}{2}\right)^{2} C_{s i}^{T} Y_{i}^{T} Y_{i} C_{s i}+\epsilon_{i}^{-1} B_{i} B_{i}^{T}\right] .
$$

Note that (48) can be easily written as an LMI with respect to unknown variables by using the Schur complement, but it is omitted here for brevity.

In addition, from (37), the constraint $\left|u_{i}\right| \leq \frac{u_{\lim i}}{\varepsilon_{i}}$ can be expressed as

$$
\left|K_{i} C_{s i} x\right| \leq \frac{u_{\lim i}}{\varepsilon_{i}} .
$$

Let $\Omega\left(K_{i}\right)=\left\{x \| x^{T} C_{s i}^{T} K_{i}^{T} K_{i} C_{s i} x \mid \leq\left(\frac{u_{\lim i}}{\varepsilon_{i}}\right)^{2}\right\}$, and the equivalent condition for an ellipsoid $\Omega(P, \rho)=\left\{x|| x^{T} P x \leq \rho\right\}$ being a subset of $\Omega\left(K_{i}\right)$, i.e., $\Omega(P, \rho) \subset \Omega\left(K_{i}\right)$, is given as (Cao and Lin, 2003). 


$$
K_{i} C_{s i}\left(\frac{P}{\rho}\right)^{-1} C_{s i}^{T} K_{i}^{T} \leq\left(\frac{u_{\lim i}}{\varepsilon_{i}}\right)^{2}
$$

Using the Schur complement, inequality (50) can be written as

$$
\left[\begin{array}{cc}
\left(\frac{u_{\lim } i}{\varepsilon_{i}}\right)^{2} I & K_{i} C_{s i}\left(\frac{P}{\rho}\right)^{-1} \\
\left(\frac{P}{\rho}\right)^{-1} C_{s i}^{T} K_{i}^{T} & \left(\frac{P}{\rho}\right)^{-1} I
\end{array}\right] \geq 0 .
$$

Using the definitions $Q=P^{-1}, W_{i} C_{s i}=C_{s i} Q$ and $Y_{i}=K_{i} W_{i}$, inequality (51) is equivalent to

$$
\left[\begin{array}{cc}
\left(\frac{u_{\lim i}}{\varepsilon_{i}}\right)^{2} I & Y_{i} C_{s i} \\
C_{s i}^{T} Y_{i}^{T} & \rho^{-1} Q
\end{array}\right] \geq 0 .
$$

It is observed that the static output feedback controller design is the feasibility problem of LMIs (48) and (52) with equality constraint $W_{i} C_{s i}=C_{s i} Q$. The equality constraint $W_{i} C_{s i}=C_{s i} Q$ can be equivalently converted to (Ho and Niu, 2007)

$$
\operatorname{tr}\left[\left(W_{i} C_{s i}-C_{s i} Q\right)^{T}\left(W_{i} C_{s i}-C_{s i} Q\right)\right]=0
$$

By introducing the condition

$$
\left(W_{i} C_{s i}-C_{s i} Q\right)^{T}\left(W_{i} C_{s i}-C_{s i} Q\right) \leq \mu I
$$

where $\mu>0$, it is then equivalent to

$$
\left[\begin{array}{cc}
-\mu I & \left(W_{i} C_{s i}-C_{S i} Q\right)^{T} \\
W_{i} C_{s i}-C_{s i} Q & -I
\end{array}\right] \leq 0,
$$

by means of the Schur complement. If we assume $\mu$ as a very small positive number, say for example $10^{-10}$, then (55) is also a LMI and can be numerically solved.

We now state the controller design problem as: for given numbers $\gamma>0, \varepsilon_{i}>0, \rho>0, \mu \approx 0$ and $u_{\lim i}$ the system (39) with controller (37) is quadratically stable and $\left\|T_{z w}\right\|_{\infty}<\gamma$ if there exist matrices $Q>0, W_{i}, Y_{i}$ and scalars $\epsilon_{i}>0$ exist in such a way that LMIs (48), (52) and (55) are feasible. Moreover, the feedback gain matrices are obtained as $K_{i}=Y_{i} W_{i}^{-1}, i=1,2, \ldots, 5$.

It is noticed that (48), (52) and (55) are LMIs to $\gamma^{2}$ and hence, to minimise the performance measure $\gamma$, the controller design problem can be modified as a minimisation problem of

$$
\min \gamma^{2} \quad \text { s.t. LMIs (48), (52) and (55). }
$$

This minimisation problem is a convex optimisation problem and can be solved by using standard software. 
Since the solution to (56) will be dependent on the values of $\varepsilon_{i}$ and $\rho$, it is a sub-optimal solution for the given $u_{\lim i}$. Choosing values for $\varepsilon_{i}$ and $\rho$ is a trial and error process. In general, using small values of $\varepsilon_{i}$ and $\rho$ may get a high gain controller design. Note that $\varepsilon_{i}$ can be chosen differently for each input and $\epsilon_{i}$ can be solved differently for each input in the problem of (56) and therefore, the feasibility of finding a solution is increased.

At last, as the ER damper is a semi-active device, the control input $u_{i}$ applied to each ER damper should have the following semi-active condition imposed:

$$
\bar{u}_{i}= \begin{cases}\bar{u}_{i} & \text { if } \bar{u}_{i}\left(\dot{z}_{s i}-\dot{z}_{u i}\right)>0, \\ 0 & \text { if } \bar{u}_{i}\left(\dot{z}_{s i}-\dot{z}_{u i}\right) \leq 0 .\end{cases}
$$

The control input is used to determine the input electric field applied to the ER damper by (Choi and Han, 2003)

$$
E_{i}=\left[u_{i} \frac{h}{2 \alpha l\left(A_{p}-A_{r}\right)}\right]^{\frac{1}{\beta}} .
$$

The control system block diagram is shown in Figure 2, where the controller $K$ needs to be obtained by solving the problem of (56), the ER dampers will be applied to provide the required damping forces and the control outputs will be used to evaluate the control system performance.

Figure 2 Diagram of the control system

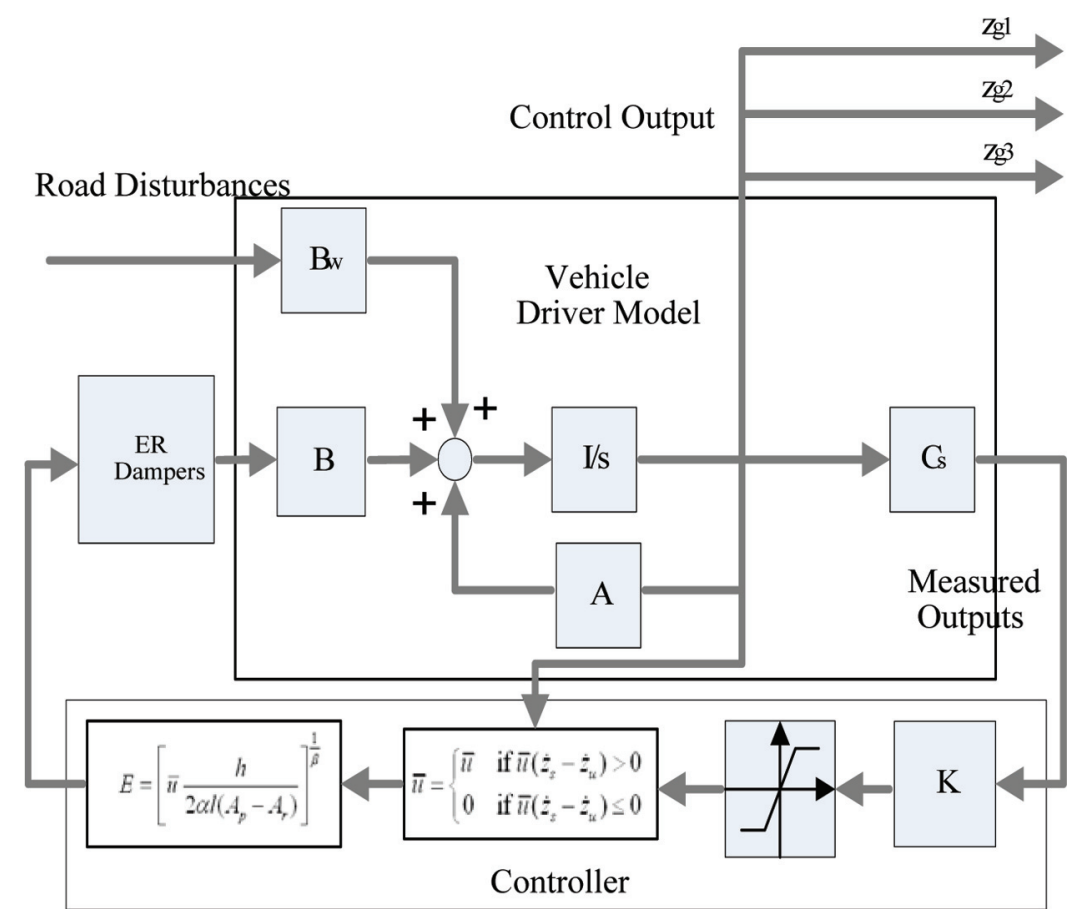




\section{Simulation results}

The effectiveness of the proposed semi-active control of the integrated system for improving driver ride comfort is evaluated by numerical simulations. The parameters for the full-car suspension are listed in Table 2 (Bouazara et al., 2006; Choi and Han, 2003), the parameters for the seat suspension and driver body model parameters are listed in Table 3 (Choi and Han, 2007) and the ER damper parameters are listed in Table 4 (Choi and Han, 2003).

Table 2 Parameter values of the full-car suspension model

\begin{tabular}{lcllcl}
\hline Parameter & Value & Unit & Parameter & Value & Unit \\
\hline$m_{s}$ & 1460 & $\mathrm{Kg}$ & $c_{s f}$ & 946 & $\mathrm{Nm} / \mathrm{s}$ \\
$I_{\theta}$ & 2460 & $\mathrm{~kg} \cdot \mathrm{m}^{2}$ & $c_{s r}$ & 946 & $\mathrm{Nm} / \mathrm{s}$ \\
$I \phi$ & 460 & $\mathrm{~kg} \cdot \mathrm{m}^{2}$ & $k_{s f}$ & 20580 & $\mathrm{~N} / \mathrm{m}$ \\
$m_{u f}$ & 40 & $\mathrm{~kg}$ & $k_{s r}$ & 20580 & $\mathrm{~N} / \mathrm{m}$ \\
$m_{u r}$ & 35.5 & $\mathrm{~kg}$ & $k_{t f}, k_{t r}$ & 175500 & $\mathrm{~N} / \mathrm{m}$ \\
$l_{f}$ & 1.011 & $\mathrm{~m}$ & $t_{f}$ & 0.761 & $\mathrm{~m}$ \\
$l_{r}$ & 1.803 & $\mathrm{~m}$ & $t_{r}$ & 0.755 & $\mathrm{~m}$ \\
$r_{x}$ & 0.3 & $\mathrm{~m}$ & $r_{y}$ & 0.25 & $\mathrm{~m}$ \\
\hline
\end{tabular}

Table 3 Parameter values of the seat and driver body model

\begin{tabular}{|c|c|c|c|c|c|}
\hline Mass $(\mathrm{kg})$ & Value & $\begin{array}{c}\text { Damping } \\
\text { coefficient }(\mathrm{Ns} / \mathrm{m})\end{array}$ & Value & $\begin{array}{c}\text { Spring stiffness } \\
(\mathrm{N} / \mathrm{m})\end{array}$ & Value \\
\hline$m_{f}$ & 15 & $c_{s s}$ & 830 & $k_{\mathrm{ss}}$ & 31000 \\
\hline$m_{c}$ & 1 & $c_{c}$ & 200 & $k_{c}$ & 18000 \\
\hline$m_{1}$ & 12.78 & $c_{1}$ & 2064 & $k_{1}$ & 90000 \\
\hline$m_{2}$ & 8.62 & $c_{2}$ & 4585 & $k_{2}$ & 162800 \\
\hline$m_{3}$ & 28.49 & $c_{3}$ & 4750 & $k_{3}$ & 183000 \\
\hline$m_{4}$ & 5.31 & $c_{4}$ & 400 & $k_{4}$ & 310000 \\
\hline
\end{tabular}

In the simulation, the maximum electric field applied to each ER damper is assumed to be 4 $\mathrm{kV} / \mathrm{mm}$, which corresponds to a damping force of $1534 \mathrm{~N}$. Hence, $u_{\text {lim }}=1534 \mathrm{~N}$ is used in the controller design for both car suspension and seat suspension.

Table 4 Parameter values of ER damper

\begin{tabular}{llllll}
\hline Parameter & Value & Unit & Parameter & Value & Unit \\
\hline$l$ & 0.258 & $\mathrm{~m}$ & $A_{p}$ & 0.00071 & $\mathrm{~m}^{2}$ \\
$h$ & 0.00075 & $\mathrm{~m}$ & $A_{r}$ & 0.00025 & $\mathrm{~m}^{2}$ \\
\hline
\end{tabular}

In terms of the measurement availability of the signals in practice, the relative velocities between the sprung and unsprung masses $\dot{z}_{s i}-\dot{z}_{u i}$, the unsprung mass displacements $z_{u i}$ and the velocities $\dot{z}_{u i}, i \in\{f l, f r, r l, r r\}$, will be used as feedback signals for the car suspension control. For the seat suspension control, the relative velocity $\dot{z}_{f}-\dot{z}_{p s}$ and the relative displacement $z_{f}-z_{p s}$ between the cabin floor and the seat frame are used as feedback 
signals. By solving the minimisation problem of (56), the static output feedback controller gain matrices for the integrated system model (39) are designed as

$$
\begin{aligned}
& K_{1}=10^{4} \times\left[\begin{array}{lllll}
-0.9261 x_{1} & -0.0666 x_{14} & 1.0629 x_{18} & -1.0746 x_{19} & 0.8089 x_{20}
\end{array}\right], \\
& K_{2}=10^{4} \times\left[\begin{array}{lllll}
0.0237 x_{2} & -0.0206 x_{15} & 0.8279 x_{18} & -0.8370 x_{19} & -0.6300 x_{20}
\end{array}\right], \\
& K_{3}=10^{4} \times\left[\begin{array}{lllll}
0.8232 x_{3} & -0.0065 x_{16} & 0.1930 x_{18} & 0.3479 x_{19} & 0.1457 x_{20}
\end{array}\right], \\
& K_{4}=10^{4} \times\left[\begin{array}{lllll}
0.7047 x_{4} & -0.0009 x_{17} & 0.1530 x_{18} & 0.2758 x_{19} & -0.1155 x_{20}
\end{array}\right], \\
& K_{5}=10^{4} \times\left[\begin{array}{lllll}
2.0881 x_{5} & -0.6264 x_{6} & 0.5220 x_{7} & -2.0881 x_{8} \\
-0.0541 x_{18} & 0.0162 x_{19} & -0.0135 x_{20} & 0.0541 x_{21}
\end{array}\right] .
\end{aligned}
$$

For description brevity, we denote this controller as Controller hereafter.

To validate the system performance in the time domain, two typical road disturbances, i.e., bump road disturbance and random road disturbance, will be considered in the simulation and applied to the vehicle's wheels.

\subsection{Comparison on bump response}

The ground displacement for an isolated bump in an otherwise smooth road surface is given by

$$
z_{r}(t)= \begin{cases}\frac{a}{2}\left(1-\cos \left(\frac{2 \pi v_{0}}{l} t\right)\right), & 0 \leq t \leq \frac{1}{v_{0}}, \\ 0, & t>\frac{1}{v_{0}}\end{cases}
$$

where $a$ and $l$ are the height and the length of the bump and $v_{0}$ is the vehicle's forward speed. We choose $a=0.08 \mathrm{~m}, l=2 \mathrm{~m}$ and $v_{0}=30 \mathrm{~km} / \mathrm{h}$ in the simulation. The bump road disturbances are shown in Figure 3, where the road disturbances to the front and rear wheels have the same peak amplitude with a time delay of $\left(l_{f}+l_{r}\right) / v_{0}$, the road disturbances to the left and right wheels are applied with different amplitude to excite the roll motion of the vehicle (Bouazara et al., 2006).

The bump responses of the driver head acceleration for the integrated system are compared in Figure 4, where Passive means no controller has been used in the system, Active means the Controller is applied to the system without the semi-active condition (57) imposed and Semi-active means the Controller is applied to the system through the ER dampers with the semi-active condition (57) applied. It can be seen from Figure 4 that the Semi-active control achieves an improved performance on ride comfort in terms of the maximum peak value of driver head acceleration compared to the Passive system. A comparison of car suspension deflections is shown in Figure 5, from which we can see that the Semi-active control generates less car suspension deflections compared to the Active control. Further comparison of the tyre deflections is shown in Figure 6. It can be seen from Figure 6 that Passive, Semi-active and Active generate similar tyre deflections. This means that Semi-Active and Active have a road holding performance similar to Passive's, while they achieve better ride comfort performance. The electric fields applied to the ER dampers for Semi-active are shown in Figure 7. It can be seen that the ER dampers installed in the car suspension consume 
more power than the ER damper installed in the seat suspension. The seat suspension assists the car suspension to improve ride comfort performance with less power consumption.

Figure 3 Bump road disturbances (see online version for colours)

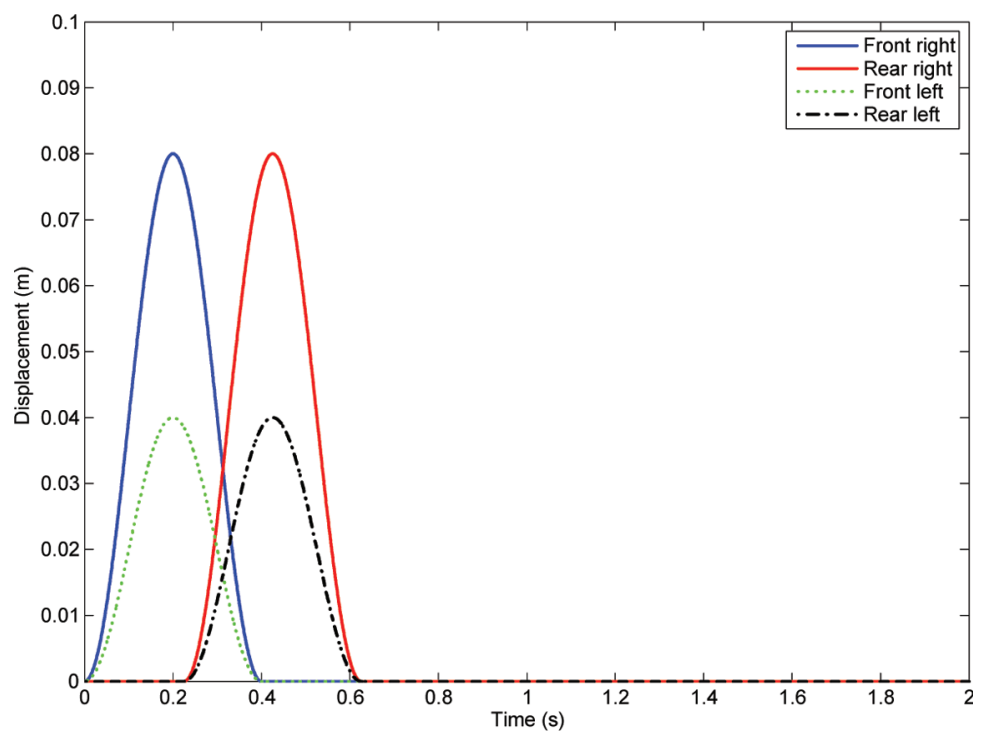

Figure 4 Bump responses on driver head acceleration for different systems (see online version for colours)

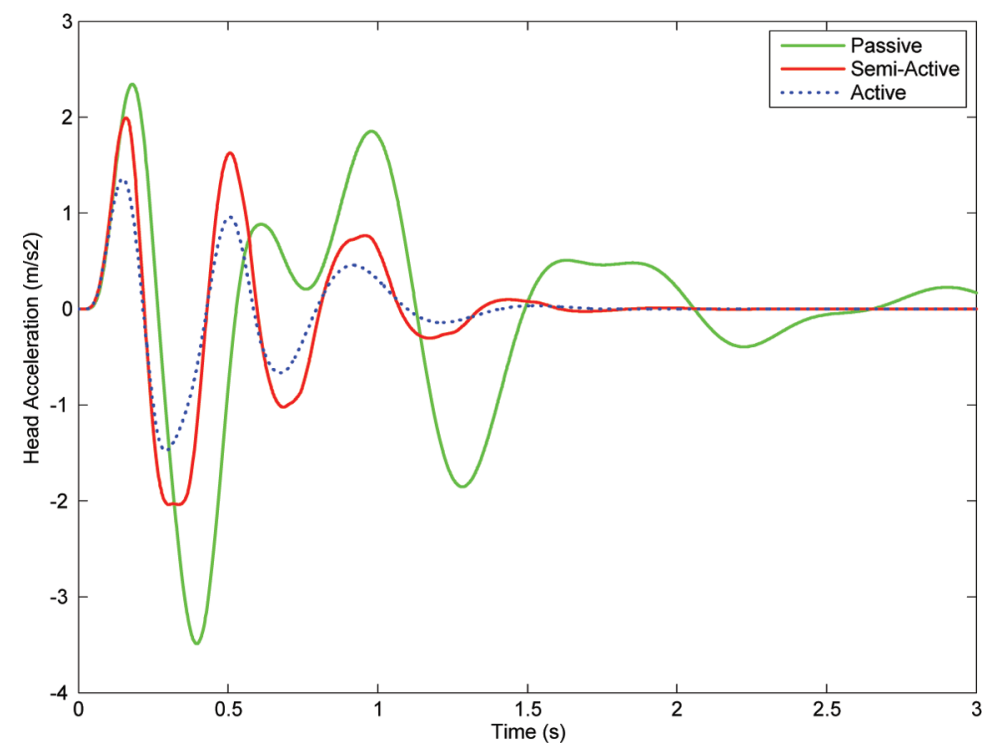


Figure 5 Bump responses on car suspension deflections for different systems (see online version for colours)
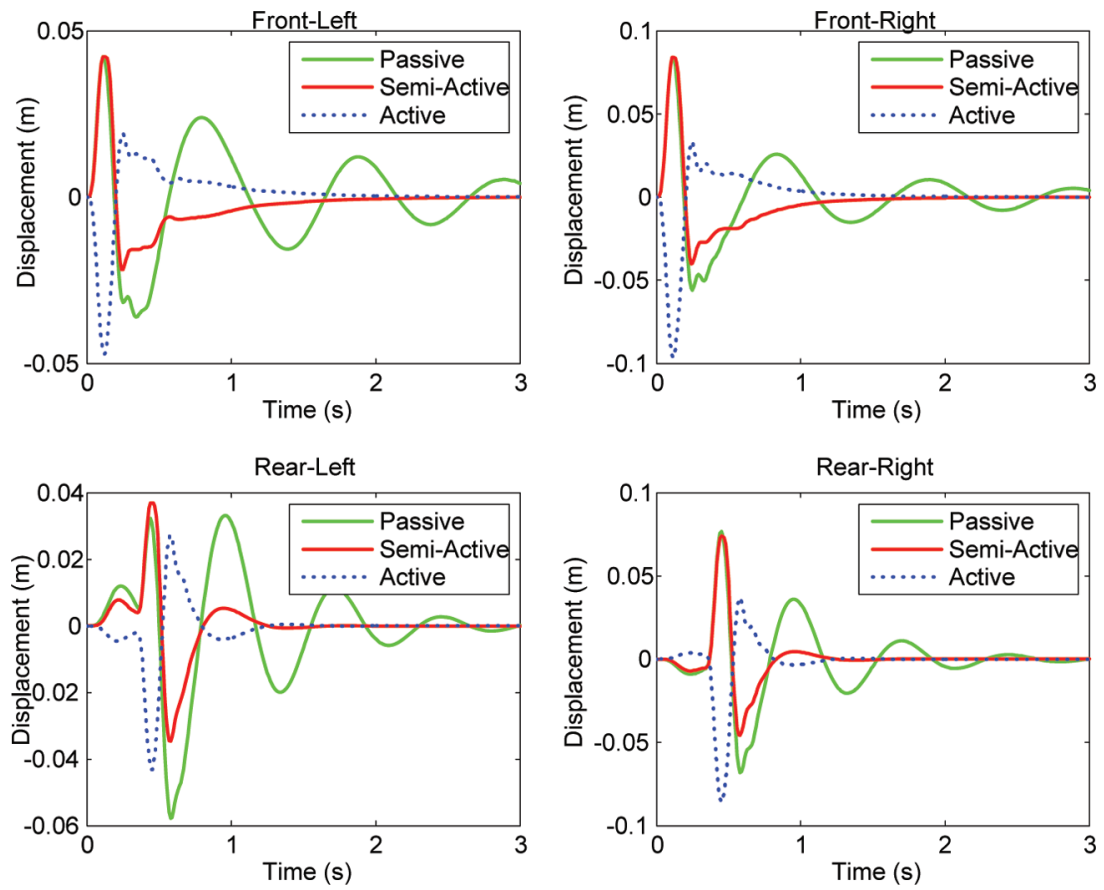

Figure 6 Bump responses on tyre deflections for different systems (see online version for colours)
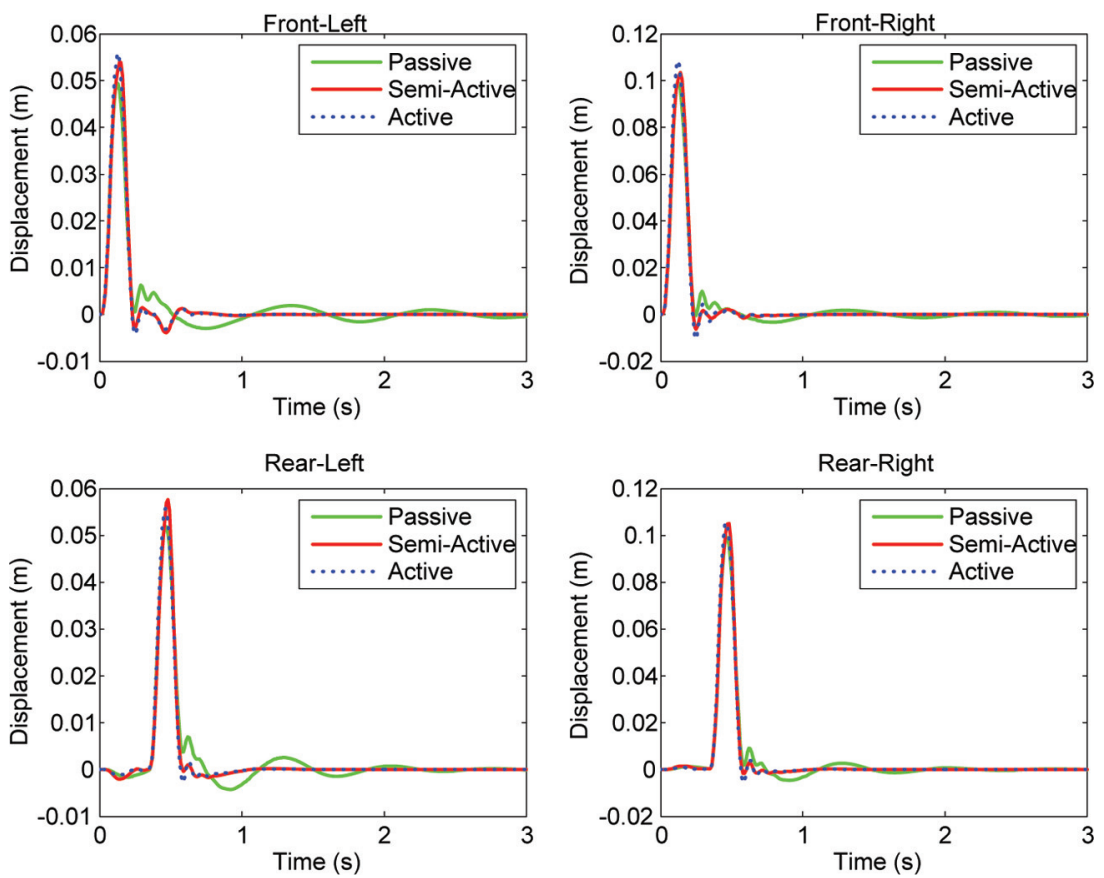
Figure 7 Electric fields applied to ER dampers under bump road disturbances for semi-active control (see online version for colours)

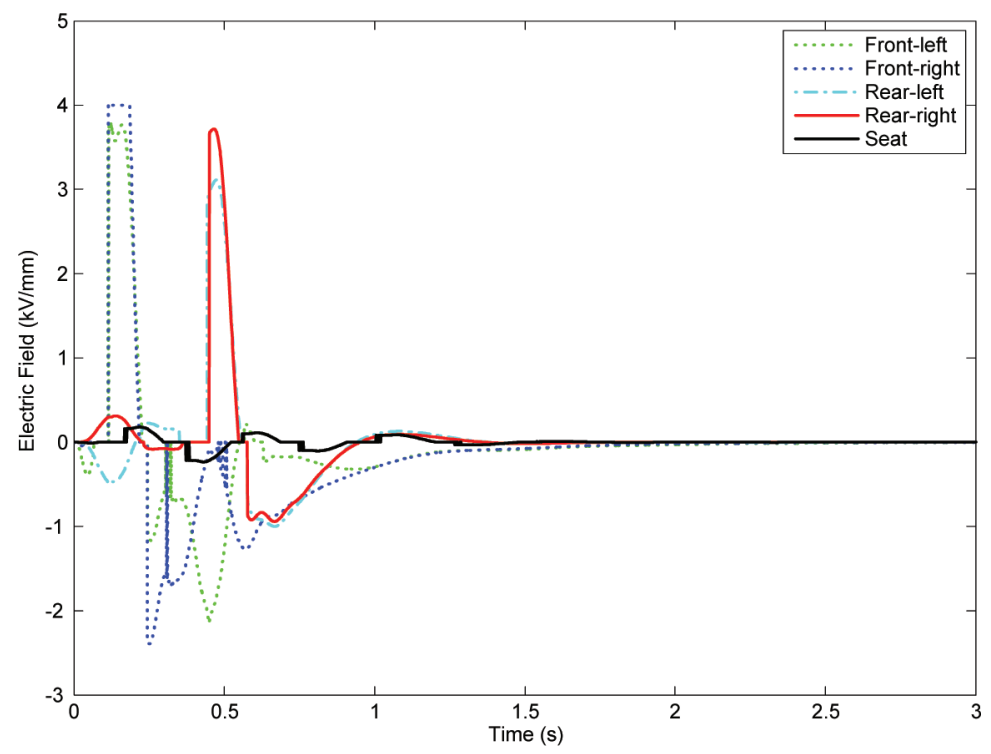

\subsection{Comparison on random response}

When the road disturbance is considered as a vibration, it is typically specified as a random process with a ground displacement Power Spectral Density (PSD) of

$$
S_{g}(\Omega)=\left\{\begin{array}{ll}
S_{g}\left(\Omega_{0}\right)\left(\frac{\Omega}{\Omega_{0}}\right)^{-n_{1}}, & \text { if } \Omega \leq \Omega_{0} \\
S_{g}\left(\Omega_{0}\right)\left(\frac{\Omega}{\Omega_{0}}\right)^{-n_{2}}, & \text { if } \Omega \geq \Omega_{0}
\end{array},\right.
$$

where $\Omega_{0}=\frac{1}{2 \pi}$ is a reference frequency, $\Omega$ is a frequency, $n_{1}$ and $n_{2}$ are road roughness constants. The value $S_{g}\left(\Omega_{0}\right)$ provides a measure for the roughness of the road. In particular, random road profile samples can be generated using the spectral representation method (Verros et al., 2005). If the vehicle is assumed to travel with a constant horizontal speed $v_{0}$ over a given road, the road's irregularities can be simulated by the following series:

$$
z_{r}(t)=\sum_{n=1}^{N_{f}} s_{n} \sin \left(n \omega_{0} t+\varphi_{n}\right),
$$

where $s_{n}=\sqrt{2 S_{g}(n \Delta \Omega) \Delta \Omega}, \quad \Delta \Omega=\frac{2 \pi}{l}, l$ is the length of the road segment, $\omega_{0}=\frac{2 \pi}{l} v_{0}$, and $\varphi_{n}$ are treated as random variables, following a uniform distribution in the interval $(0$, $2 \pi) . N_{f}$ limits the considered frequency range.

To validate the effectiveness of different systems under different road conditions and different vehicle speeds, we use $n_{1}=2, n_{2}=1.5, l=200, N_{f}=200$ in equations (65) and (66) 
and select the road roughness as $S_{g}\left(\Omega_{0}\right)=64 \times 10^{-6} \mathrm{~m}^{3}$ (C Grade, Average), $S_{g}\left(\Omega_{0}\right)=256 \times 10^{-6} \mathrm{~m}^{3}$ (D Grade, Poor) and $S_{g}\left(\Omega_{0}\right)=1024 \times 10^{-6} \mathrm{~m}^{3}$ (E Grade, Very Poor), respectively, according to ISO 2631 standards. We also choose speeds from $60 \mathrm{~km} / \mathrm{h}$ to $100 \mathrm{~km} / \mathrm{h}$ with intervals at $10 \mathrm{~km} / \mathrm{h}$. Taking into account the random nature of the road input, the Root Mean Square (RMS) of the driver head acceleration is used as a performance index to compare the performance of different systems on ride comfort. The simulation will be randomly run 50 times to calculate the expectation of RMS values for the driver head acceleration and the results for different systems under four different road profiles and five different speeds are compared in Figures 8-11. It can be observed from Figures 8-11 that the Semi-active control always outperforms the Passive system while achieving similar performance to the Active control, despite the changes in road conditions and speeds.

Figure 8 RMS of driver head acceleration under B Grade road disturbance at different speeds for different systems (see online version for colours)

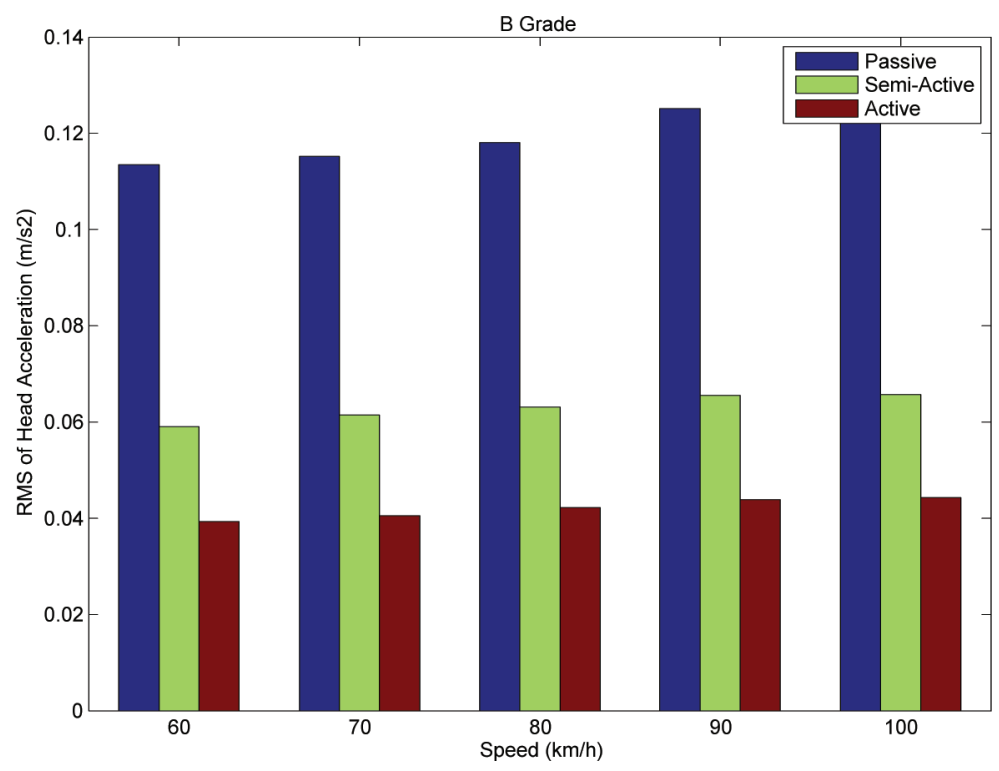

\section{Conclusions}

This paper presents the suspension control of an integrated system to enhance ride comfort performance. The ER damper is adopted to achieve the semi-active control objective. Since the integrated system includes a full-car suspension model, a seat suspension model and a driver body model, five ER dampers are required. To design an integrated controller for the five ER dampers, LMI conditions are derived by dealing with each control input separately so that a feasible solution could be found. At the same time, different feedback signals can be chosen for different control inputs in terms of their positions and availability in the system. Numerical simulations are used to validate the performance of the designed controllers. The results show that the integrated semi-active control can provide a better ride comfort performance compared to passive systems. 
Figure 9 RMS of driver head acceleration under $\mathrm{C}$ Grade road disturbance at different speeds for different systems (see online version for colours)

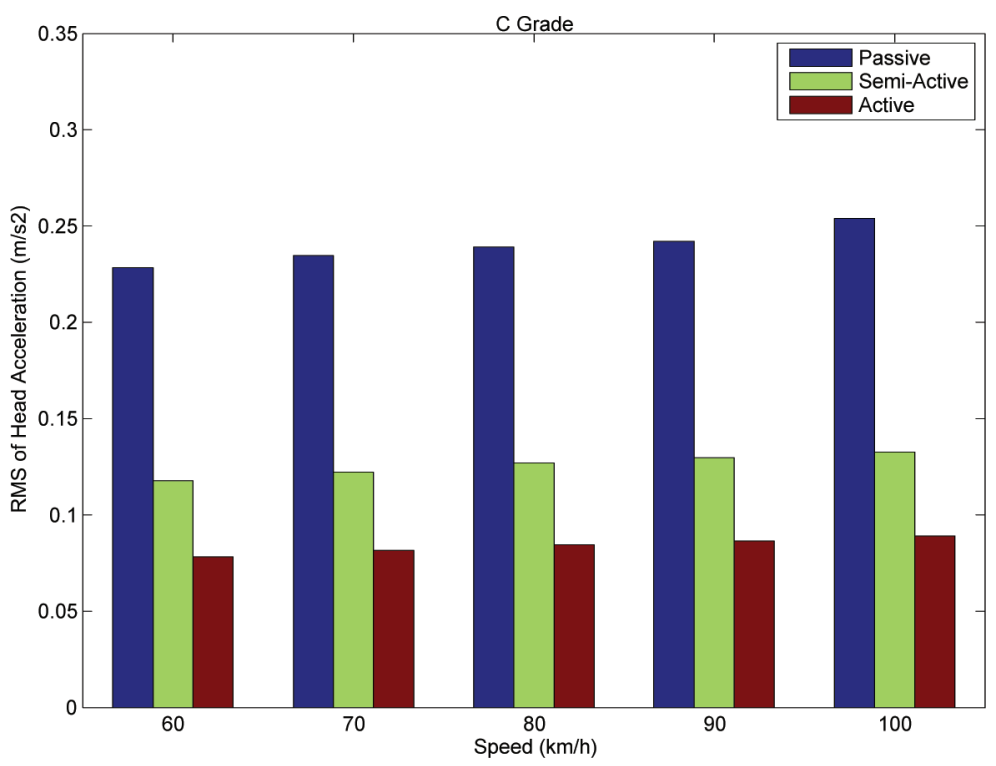

Figure 10 RMS of driver head acceleration under D Grade road disturbance at different speeds for different systems (see online version for colours)

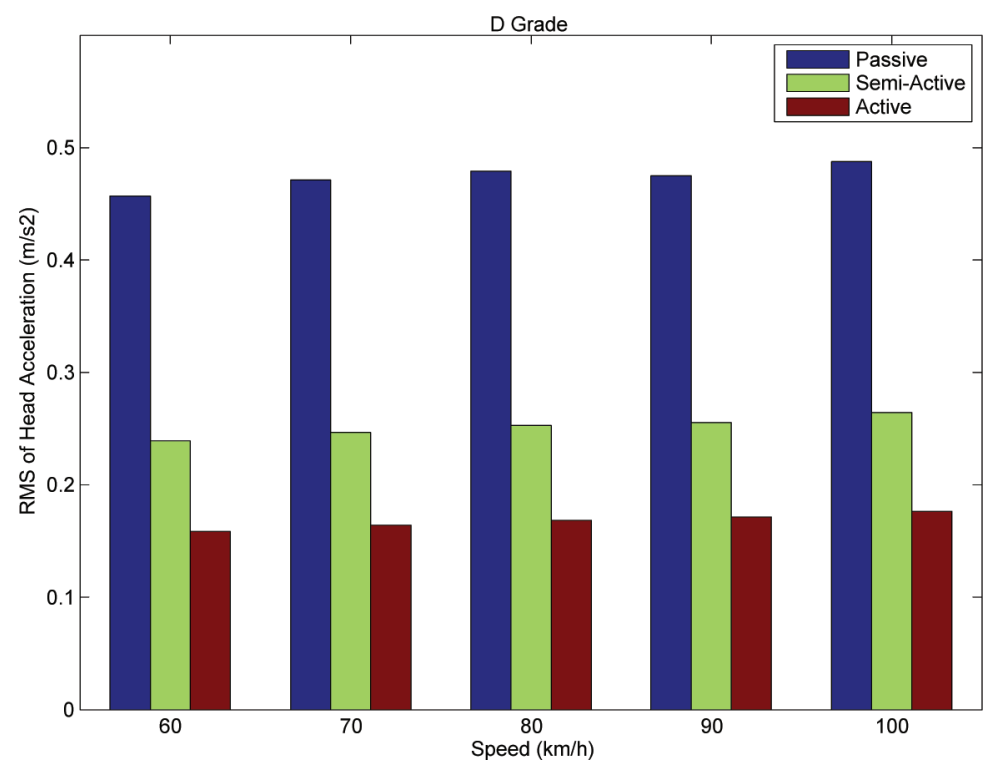


Figure 11 RMS of driver head acceleration under E Grade road disturbance at different speeds for different systems

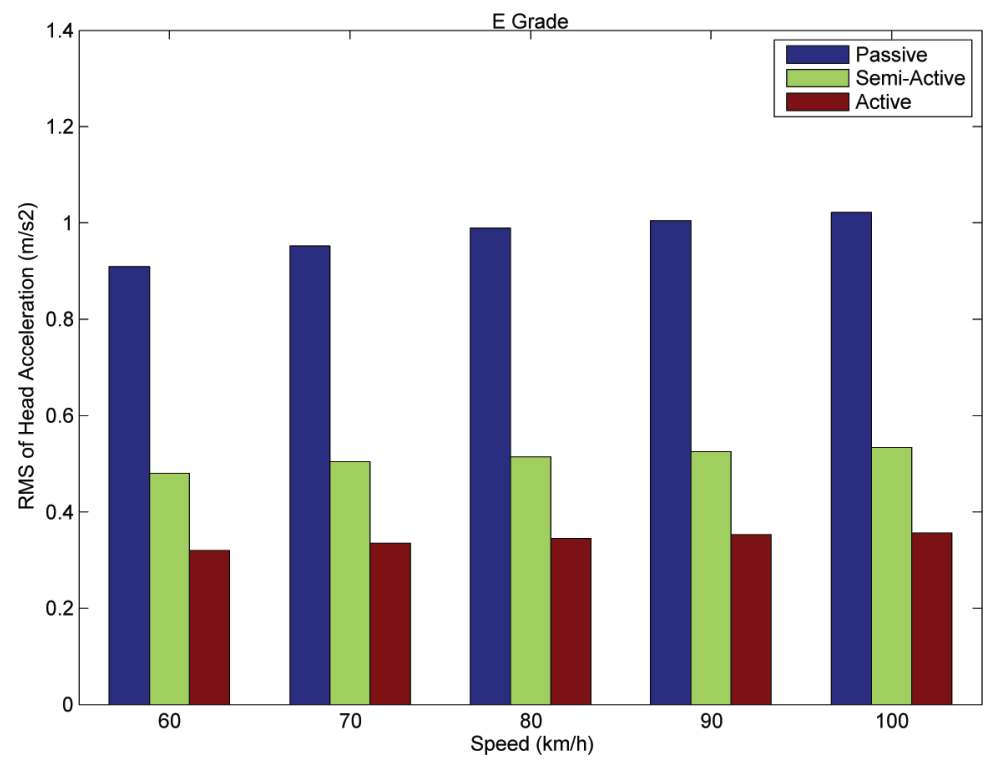

\section{References}

Bouazara, M., Richard, M.J. and Rakheja, S. (2006) 'Safety and comfort analysis of a 3-D vehicle model with optimal non-linear active seat suspension', Journal of Terrame-Chanics, Vol. 43, pp.97-118.

Boyd, S., El Ghaoui, L., Feron, E. and Balakrishnan, V. (1994) Linear Matrix Inequalities in System and Control Theory, SIAM, Philadelphia, June, PA.

Cao, Y-Y. and Lin, Z. (2003) 'Robust stability analysis and fuzzy-scheduling control for nonlinear systems subject to actuator saturation', IEEE Transactions on Fuzzy Systems, Vol. 11, No. 1, pp.57-67.

Choi, S.B. and Han, S.S. (2003) ' $H_{\infty}$ control of electrorheological suspension system subjected to parameter uncertainties', Mechtronics, Vol. 13, pp.639-657.

Choi, S.B., Choi, Y.T. and Park, D.W. (2000) 'A sliding mode control of a full-car electrorheological suspension system via hardware in-the-loop simulation', Journal of Dynamic Systems, Measurement, and Control, Vol. 122, No. 1, pp.114-121.

Choi, S.B. and Kim, W.K. (2000) 'Vibration control of a semi-active suspension featuring electrorheological fluid dampers', Journal of Sound and Vibration, Vol. 234, pp.537-546.

Choi, S.B., Choi, J.H., Lee, Y.S. and Han, M.S. (2003) 'Vibration control of an ER seat suspension for a commercial vehicle', Journal of Dynamic Systems, Measurement and Control, Vol. 125, pp.60-68.

Choi, S.B., Lee, H.S. and Park, Y.P. (2002) ' $H_{\infty}$ control performance of a full-vehicle suspension featuring magnetorheological dampers', Vehicle System Dynamics, Vol. 38, No. 5, pp.341-360.

Choi, S-B. and Han, Y-M. (2007) 'Vibration control of electrorheological seat suspension with human-body model using sliding mode control', Journal of Sound and Vibration, Vol. 303, pp.391-404.

Choi, S-B., Nam, M-H. and Lee, B-K. (2000) 'Vibration control of a MR seat damper for commercial vehicle', Journal of Intelligent Material Systems and Structures, Vol. 11, pp.936-944. 
Choi, Y-T. and Wereley, N.M. (2005) 'Mitigation of biodynamic response to vibratory and blast-induced shock loads using magnetorheological seat suspensions', Proceedings of the Institution of Mechanical Engineers, Part D: Journal of Automobile Engineering, Vol. 219, pp.741-753.

Du, H., Sze, K.Y. and Lam, J. (2005) 'Semi-active $H_{\infty}$ control of vehicle suspension with magnetorheological dampers', Journal of Sound and Vibration, Vol. 283, pp.981-996.

Fallah, M.S., Bhat, R. and Xie, W.F. (2009) 'New model and simulation of Macpherson suspension system for ride control applications', Vehicle System Dynamics, Vol. 47, No. 2, pp.195-220.

Guglielmino, E., Sireteanu, T., Stammers, C.W., Ghita, G. and Giuclea, M. (2008) Semi-active Suspension Control - Improved Vehicle Ride and Road Friendliness, Springer, London.

Gundogdu, O. (2007) 'Optimal seat and suspension design for a quarter car with driver model using genetic algorithms', International Journal of Industrial Ergonomics, Vol. 37, pp.327-332.

Han, Y.M., Jung, J.Y., Choi, S.B., Choi, Y.T. and Wereley, N.M. (2006) 'Ride quality investigation of an electrorheological seat suspension to minimize human body vibrations', Proceedings of the Institution of Mechanical Engineers, Part D: Journal of Automobile Engineering, Vol. 220, No. 2, pp.139-150.

Ho, D.W.C. and Niu, Y. (2007) 'Robust fuzzy design for nonlinear uncertain stochastic systems via sliding-mode control', IEEE Transactions on Fuzzy Systems, Vol. 15, No. 3, pp.350-358.

Hrovat, D. (1997) 'Survey of advanced suspension developments and related optimal control applications', Automatica, Vol. 33, No. 10, pp.1781-1817.

Kim, J.H. and Jabbari, F. (2002) 'Actuator saturation and control design for buildings under seismic excitation', Journal of Engineering Mechanics, Vol. 128, No. 4, pp.403-412.

Kuznetsov, A., Mammadov, M., Sultan, I. and Hajilarov, E. (2011) 'Optimization of a quarter-car suspension model coupled with the driver biomechanical effects', Journal of Sound and Vibration, Vol. 330, pp.2937-2946.

Lee, C-M., Bogatchenkov, A.H., Goverdovskiy, V.N., Shynkarenko, Y.V. and Temnikov, A.I. (2006) 'Position control of seat suspension with minimum stiffness', Journal of Sound and Vibration, Vol. 292, pp.435-442.

Maciejewski, I., Meyer, L. and Krzyzynski, T. (2010) 'The vibration damping effectiveness of an active seat suspension system and its robustness to varying mass loading', Journal of Sound and Vibration, Vol. 329, No. 19, pp.3898-3914.

Poussot-Vassal, C., Sename, O., Dugard, L., Gaspar, P., Szabo, Z. and Bokor, J. (2008) 'A new semi-active suspension control strategy through LPV technique', Control Engineering Practice, Vol. 16, pp.1519-1534.

Sun, W., Li, J., Zhao, Y. and Gao, H. (2011) 'Vibration control for active seat suspension systems via dynamic output feedback with limited frequency characteristic', Mecha-tronics, Vol. 21, pp.250-260.

Sung, K.G., Han, Y.M., Cho, J.W. and Choi, S.B. (2008) 'Vibration control of vehicle ER suspension system using fuzzy moving sliding mode controller', Journal of Sound and Vibration, Vol. 311, pp.1004-1019.

Sung, K.G., Han, Y.M., Lim, K.H. and Choi, S.B. (2007) 'Discrete-time fuzzy sliding mode control for a vehicle suspension system featuring an electrorheological fluid damper', Smart Materials and Structures, Vol. 16, pp.798-808.

Tiemessen, I.J., Hulshof, C.T.J. and Frings-Dresen, M.H.W. (2007) 'An overview of strategies to reduce whole-body vibration exposure on drivers: a systematic review', International Journal of Industrial Ergonomics, Vol. 37, pp.245-256.

Verros, G., Natsiavas, S. and Papadimitriou, C. (2005) 'Design optimization of quarter-car models with passive and semi-active suspensions under random road excitation', Journal of Vibration and Control, Vol. 11, pp.581-606.

Wan, Y. and Schimmels, J.M. (2003) 'Improved vibration isolating seat suspension designs based on position-dependent nonlinear stiffness and damping characteristics', Journal of Dynamic Systems, Measurement and Control, Vol. 125, No. 3, pp.330-338. 
Wang, J., Dong, C., Shen, Y. and Wei, J. (2008) 'Robust modelling and control of vehicle active suspension with MR damper', Vehicle System Dynamics, Vol. 46, pp.509-520.

Williams, R.A. (1997) 'Automotive active suspensions', Proceedings of the Institution of Mechanical Engineers, Part D: Journal of Automobile Engineering, Vol. 211, No. 6, pp.415-444.

Wu, J-D. and Chen, R-J. (2004) 'Application of an active controller for reducing small-amplitude vertical vibration in a vehicle seat', Journal of Sound and Vibration, Vol. 274, pp.939-951.

Yu, M., Dong, X.M., Choi, S.B. and Liao, C.R. (2009) 'Human simulated intelligent control of vehicle suspension system with MR dampers', Journal of Sound and Vibration, Vol. 319, pp.753-767.

Zhao, Y., Zhao, L. and Gao, H. (2010) 'Vibration control of seat suspension using reliable control', Journal of Vibration and Control, Vol. 16, No. 12, pp.1859-1879.

Zhou, K. and Khargonekar, P.P. (1988) 'An algebraic Riccati equation approach to $H_{\infty}$ optimization', Systems and Control Letters, Vol. 11, pp.85-91. 